\title{
Adenocarcinoma of Ascending Colon Associated with Sarcoid Reaction in Regional Lymph Nodes
}

\author{
Takaaki Fujii Yuichi Tabe Reina Yajima Soichi Tsutsumi \\ Takayuki Asao Hiroyuki Kuwano \\ Department of General Surgical Science, Graduate School of Medicine, Gunma \\ University, Maebashi, Japan
}

\section{Key Words}

Sarcoid reaction - Colon carcinoma - Lymph node - Epithelioid granuloma

\begin{abstract}
Lymph node swelling in the setting of malignancy generally suggests metastasis of the primary tumor. A granulomatous reaction, i.e. sarcoid reaction, occurring within the lymph nodes draining carcinomas is a well-known but uncommon occurrence. The phenomenon is especially rarely seen in colon carcinoma. We herein report a rare case of a 56-year-old Japanese male with adenocarcinoma of the ascending colon associated with sarcoid reaction in the regional lymph nodes. A typical ileocecal resection and lymph node dissection were performed. Histopathological examination revealed moderately differentiated adenocarcinoma of the ascending colon, and the dissected lymph nodes included epithelioid granulomas with multinucleated giant cells. These findings suggest the existence of a sarcoid reaction associated with colon carcinoma; there was no metastasis in the dissected lymph nodes. The significance of this rare condition is discussed.
\end{abstract}

\section{Introduction}

Sarcoidosis is a common systemic disorder of unknown etiology which is characterized by the formation of noncaseating epithelioid cell granulomas. In addition to their occurrence in systemic sarcoidosis, these granulomas have also been observed in various parenchymas and in the lymph nodes associated with other granulomatous diseases. Granulomatous reactions occurring within lymph nodes draining carcinomas are a well-known but uncommon occurrence [1-3]. These histologic changes have been termed sarcoid reactions, and such changes have been described in association with lymphoma 
and other solid tumors [4-9]. However, the presence of this response in colorectal cancer has been considered to be quite rare, and only a few reports have mentioned the presence of granulomatous reactions in colorectal cancer [10-12]. We herein report a rare case of adenocarcinoma of the ascending colon associated with sarcoid reaction in the regional lymph nodes.

\section{Case Report}

A 56-year-old Japanese man was assessed for anemia. Computed tomography of the abdomen performed to investigate the cause of anemia showed a tumor mass in his ascending colon and many enlarged regional lymph nodes (fig. 1). Colonoscopy showed a tumor encircling the ileocecal valve. There was no clinical indication of inflammatory bowel disease. Laboratory data showed no abnormality except for anemia, with $9.0 \mathrm{mg} / \mathrm{dl}$ hemoglobin. There was no elevation of the tumor markers CEA and CA19-9. Chest X-ray showed no evidence of lymphadenopathy. The past clinical history mentioned hypertension, but neither inflammatory nor immunological disease. A typical ileocecal resection and lymph node dissection were performed.

Gross examination of the operative specimen revealed a tumor measuring $70 \times 55 \mathrm{~mm}$ at the ileocecal valve, and many enlarged regional lymph nodes were present, suggesting metastasis of the lymph nodes. Histopathological examination revealed moderately differentiated adenocarcinoma of the ascending colon which extended to the subserosa. There was no metastasis to the dissected lymph nodes; however, noncaseous epithelioid granulomas with multinucleated giant cells without necrosis were observed (fig. 2). The histological findings suggested a sarcoid reaction associated with colon carcinoma. Ziehl-Neelson stains were negative, and fungal stains were not performed. The postoperative course was uneventful, and the patient was discharged from the hospital. He has been alive for 4 months without any recurrence of the tumor.

\section{Discussion}

We here report a rare case of adenocarcinoma of the ascending colon associated with sarcoid reaction in the regional lymph nodes. An association of sarcoid reaction with malignancy has been reported, and such reactions may occur in lymph nodes draining an area housing a malignant tumor, in the tumor itself, and even in nonregional tissues [13]. Sarcoid reactions have been described in association with lymphoma, testicular cancer and other solid tumors [4-9]. Overall, sarcoid reactions occur in 4.4\% of carcinomas [3]. However, this response in colorectal cancer has been considered to be quite rare, and there have been only a few publications that mention the presence of granulomatous reaction in colorectal cancer [10-12].

The mechanism of tumor-associated sarcoid reaction in the regional nodes has not yet been elucidated. The possible mechanisms are summarized as follows: (1) a localized defense reaction to tumor cells themselves, (2) a simple tissue reaction to a tumor embolism in the lymphatic system or capillaries, and (3) an immunological reaction to substances released from the tumors transported along the lymphatic system $[2,3,6,13,14]$. Sarcoidosis has been considered to be a disease closely associated with immunologic disorders [15]. Sarcoid reaction has also been reported after interferon therapy in patients with malignant melanoma and after interleukin-2 therapy for renal cell carcinoma $[16,17]$. Thus, sarcoid reactions are most likely caused by antigenic factors derived from the tumor cells and could play an important role in the host's defenses against metastatic extension [3]. Sarcoid reactions may manifest as local T-cell-mediated reactions, and in Hodgkin's disease and gastric cancer there is evidence that patients with sarcoid reactions in the regional lymph nodes have a better prognosis [18-20]. It has been generally reported that patients with malignant tumors coexisting with sarcoid reactions 
have a good prognosis because this reaction commonly occurs in lymph nodes without metastasis [3, 6]. In fact, in our case and a few case reports of colon cancer with sarcoid reactions in the lymph nodes, there was no metastatic carcinoma in the dissected lymph nodes despite the large size of the tumor. In contrast, however, according to the few publications that mention lung-cancer-associated sarcoid reaction, such lesions do not influence the prognosis $[6,21]$. To elucidate the relationship between this reaction and the prognosis of patients with cancer, especially colon cancer, an investigation based on a larger number of patients is required.

Swollen lymph nodes caused by a sarcoid reaction often mimic metastatic lymph nodes. FDG-PET is useful for preoperative diagnosis of distant lymph node metastases of colorectal cancers $[22,23]$. In present case, 18F-FDG-PET was not performed. Although $18 \mathrm{~F}-\mathrm{FDG}$-PET is very sensitive for a variety of malignancies, it can lack specificity. In addition to malignant tissue, any active infectious or inflammatory process, including sarcoidosis, can demonstrate FDG avidity $[6,24,25]$. Thus, it is difficult to differentiate sarcoid reaction from lymph node metastases preoperatively, and there is no useful examination, except histopathological examination, for distinguishing lymphadenopathy caused by a sarcoid reaction from metastatic lymph nodes.

In conclusion, we report a rare case of colon cancer with sarcoid reaction in the regional lymph nodes. Tumor-associated sarcoid reactions may represent an immune response to the cancer. The effect of the response on the prognosis in cases with colon cancer has not been fully elucidated due to the small number of such cases, and further analyses from a large number of cases are warranted to evaluate the relationship between sarcoid reaction and colon cancer.

Fig. 1. Computed tomography of the abdomen showed a mass at the cecum and enlarged regional lymph nodes.

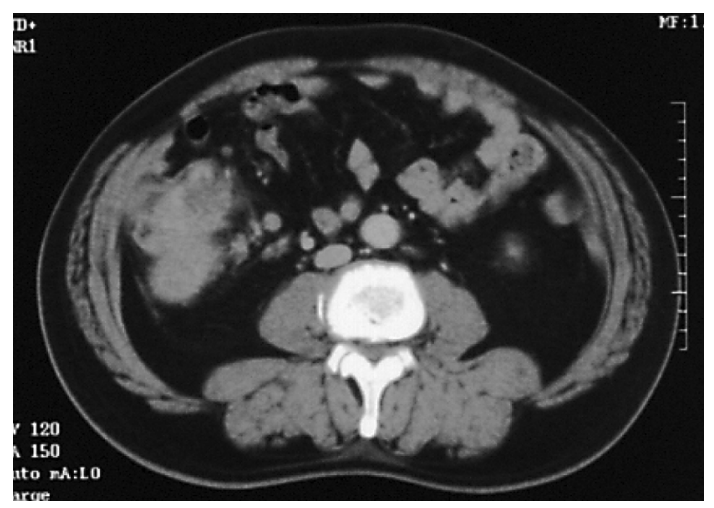




\begin{tabular}{r|l|l|l}
$\begin{array}{r}\text { Case Reports in } \\
\text { Gastroenterology }\end{array}$ & $\begin{array}{l}\text { Case Rep Gastroenterol 2010;4:118-123 } \\
\text { Dol: 10.1159/000275064 }\end{array}$ & Published online: March 20, 2010 & $\begin{array}{l}\text { I 2010 S. Karger AG, Basel } \\
\text { ISSN 1662-0631 } \\
\text { www.karger.com/crg }\end{array}$ \\
\hline
\end{tabular}

Fig. 2. Histopathological findings in the dissected lymph node showed epithelioid cell granulomas (arrows) (a) with polynuclear giant cells but without central caseous necrosis (b), suggesting a sarcoid reaction. There were no metastatic foci in the lymph nodes. HE stain. $\mathbf{a} \times 50, \mathbf{b} \times 200$.
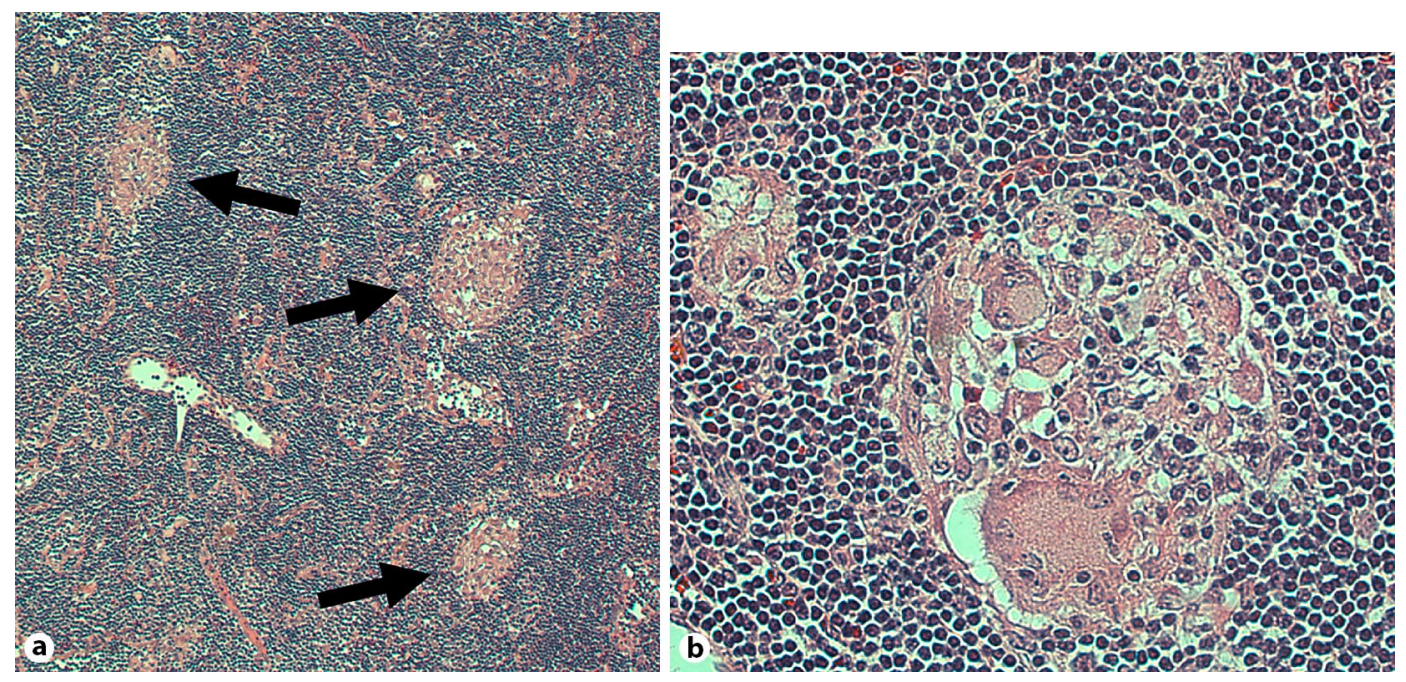


\section{References}

1 Gregorie HB, Othersen HB, Moore MP: The significance of sarcoid-like lesions in association with malignant neoplasms. Am J Surg 1962;104:577-586.

2 Gorton G, Linell F: Malignant tumors and sarcoid reactions in regional lymph nodes. Acta Radiol 1996;47:381-392.

3 Brincker H: Sarcoid reactions in malignant tumors. Cancer Treat Rev 1986;13:147-156.

4 Ludvikova M, Ryska A, Drovakova E: Focal sarcoid-like change of the thyroid gland. A possible consequence of aspiration cytology? Pathol Res Pract 2002;198:479-482.

5 Ryska A, Seifert G: Adenolymphoma (Whartin's tumor) with multiple sarcoid-like granulomas. Pathol Res Pract 1999;195:835-839.

6 Tomimaru Y, Higashiyama M, Okami J, Oda K, Takami K, Kodama K, Tsukamoto Y: Surgical results of lung cancer with sarcoid reaction in regional lymph nodes. Jpn J Clin Oncol 2007;37:90-95.

-7 Piscioli I, Donato S, Morelli L, Del Nonno F, Licci S: Renal cell carcinoma with sarcomatoid features and peritumoral sarcoid-like granulomatous reaction: report of a case and review of the literature. Int J Surg Pathol 2008;16:345-348.

-8 Onitsuka A, Katagiri Y, Kiyama S, Mimoto H, Nakamura T, Toda K, Shima H: Hilar cholangiocarcinoma associated with sarcoid reaction in the regional lymph nodes. J Hepatobiliary Pancreat Surg 2003;10:316-320.

9 Hirota T, Kaneda M, Iwasa M, Tamaki H: A case report of gastric cancer associated with sarcoid reactions in the regional lymph nodes and liver. Surg Today 1993;23:810-815.

10 Nozoe T, Matsumata T, Sugimachi K: Carcinoma in villous adenoma of ascending colon associated with sarcoid reaction in the regional lymph nodes. J Clin Gastroenterol 1999;28:377-379.

-11 Mohamadnejad M, Babai M, Bidari A, Malekzadeh R, Tavangar SM: Adenocarcinoma of the colon associated with sarcoidosis. MedGenMed 2003;5:6.

$\checkmark 12$ Coyne JD: Colonic carcinoma with granulomatous (sarcoid) reaction. J Clin Pathol 2002;55:708-709.

13 Gherardi GJ: Localized lymph node sarcoidosis associated with carcinoma of the bile ducts; report of a case. AMA Arch Pathol 1950;49:163-168.

14 Shimosato Y, Oboshi S, Umegaki Y: Tuberculoid granulomas in lymph nodes irradiated for metastatic tumors. Acta Pathol Jpn 1965;15:339-353.

15 Reynolds HY: Sarcoidosis: impact of other illnesses on the presentation and management of multi-organ disease. Lung 2002;180:281-299.

16 Massaguer S, Sánchez M, Castel T: Mediastinal sarcoidosis induced by high-dose alpha-2-interferon therapy in a patient with malignant melanoma. Eur Radiol 2004;14:1716-1717.

17 Logan TF, Bensadoun ES: Increased disease activity in a patient with sarcoidosis after high dose interleukin 2 treatment for metastatic renal cancer. Thorax 2005;60:610-611.

18 O'Connell MJ, Schimpff SC, Kirschner RH, Abt AB, Wiernik PH: Epithelioid granulomas in Hodgin disease. A favorable prognostic sign? JAMA 1975;233:886889.

19 Sacks EL, Donaldson SS, Gordon J, Dorfman RF: Epithelioid granulomas associated with Hodgkin's disease: clinical correlations in 55 previously untreated patients. Cancer 1978;41:562-567.

20 Takeuchi H, Suchi T, Suzuki R, Sato T: Histological study of immune parameters of regional lymph nodes of gastric cancer patients. Gann 1982;73:420-428.

21 Kamiyoshihara M, Hirai T, Kawashima O, Ishikawa S, Morishita Y: Sarcoid reactions in primary pulmonary carcinoma: report of seven cases. Oncol Rep 1998;5:177-180.

22 Tsunoda Y, Ito M, Fujii H, Kuwano H, Saito N: Preoperative diagnosis of lymph node metastases of colorectal cancer by FDG-PET/CT. Jpn J Clin Oncol 2008;38:347-353.

23 Kosugi C, Saito N, Murakami K, Ochiai A, Koda K, Ono M, Ito M, Oda K, Seike $\mathrm{K}$, Miyazaki M: Positron emission tomography for preoperative staging in 
patients with locally advanced or metastatic colorectal adenocarcinoma in lymph node metastasis. Hepatogastroenterology 2008;55:398-402.

24 Maeda J, Ohta M, Hirabayashi H, Matsuda H: False positive accumulation in $18 \mathrm{~F}$ fluorodeoxyglucose positron emission tomography scan due to sarcoid reaction following induction chemotherapy for lung cancer. Jpn J Thorac Cardiovasc Surg 2005;53:196-198.

25 Ataergin S, Arslan N, Ozet A, Ozguven MA: Abnormal FDG uptake on $18 \mathrm{~F}$-fluorodeoxyglucose positron emission tomography in patients with cancer diagnosis: case reports of tuberculous lymphadenitis. Intern Med 2009;48:115119 . 